Check for updates

Cite this: Chem. Commun., 2018, 54, 11336

Received 25th August 2018 Accepted 11th September 2018

DOI: $10.1039 / c 8 c c 06917 d$

rsc.li/chemcomm

\section{ESIPT-based fluorescence probe for the rapid detection of peroxynitrite 'AND' biological thiols $\uparrow$}

\author{
Luling Wu, (D) $\ddagger^{a}$ Hai-Hao Han, (D) $\ddagger^{b}$ Liyuan Liu, (D) ${ }^{a}$ Jordan E. Gardiner, (D) ${ }^{a}$ \\ Adam C. Sedgwick, (D) ac Chusen Huang, (D)*d Steven D. Bull, (D)*a \\ Xiao-Peng $\mathrm{He}\left(\mathbb{D} *^{\mathrm{b}}\right.$ and Tony D. James (D) ${ }^{a}$
}

An ESIPT-based 'AND' logic fluorescence probe (GSH-ABAH) was developed for the simultaneous detection of $\mathrm{ONOO}^{-}$and biological thiols. GSH-ABAH was shown to have good cell permeability and with the addition of just SIN-1 (ONOO ${ }^{-}$donor) or GSH, no fluorescence response was observed in live cells. However, in the presence of both analytes GSH-ABAH could be used to image exogenous

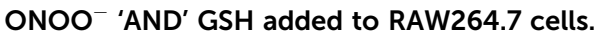

Peroxynitrite $\left(\mathrm{ONOO}^{-}\right)$is a highly reactive nitrogen species ${ }^{1}$ with an incredibly short biological half-life $(<10 \mathrm{~ms}){ }^{2} \mathrm{ONOO}^{-}$ is known for its deleterious effects, causing irreversible damage to a range of biological targets such as lipids, proteins and nucleic acids. ${ }^{3}$ As a result, abnormal concentrations of $\mathrm{ONOO}^{-}$ are thought to be associated with inflammation, cancer, atherosclerosis and neurodegenerative diseases. ${ }^{4-7}$ In addition, biological thiols such as glutathione (GSH) and cysteine (Cys) are essential in maintaining biological redox homeostasis..$^{8-10}$

GSH is a natural tripeptide ( $\gamma$-- -glutamyl-cysteinyl-glycine) that exists in the thiol reduced form (GSH) and disulphideoxidised (GSSG) form. ${ }^{11}$ GSH is the predominant form, which exists in mammalian and eukaryotic cells where it functions as an antioxidant. ${ }^{12-14}$ More importantly, GSH serves as an $\mathrm{ONOO}^{-}$scavenger through its direct oxidation by $\mathrm{ONOO}^{-}{ }^{15}$

\footnotetext{
${ }^{a}$ Department of Chemistry, University of Bath, Bath, BA2 7AY, UK.

E-mail: t.d.james@bath.ac.uk, s.d.bull@bath.ac.uk

${ }^{b}$ Key Laboratory for Advanced Materials and Joint International Research Laboratory of Precision Chemistry and Molecular Engineering, Feringa Nobel Prize Scientist Joint Research Center, School of Chemistry and Molecular Engineering, East China University of Science and Technology, 130 Meilong Rd., Shanghai 200237, China. E-mail: xphe@ecust.edu.cn

${ }^{c}$ Department of Chemistry, University of Texas at Austin, 105 E 24th Street A5300, Austin, TX 78712-1224, USA

${ }^{d}$ The Education Ministry Key Laboratory of Resource Chemistry, Shanghai Key Laboratory of Rare Earth Functional Materials, and Shanghai Municipal Education Committee Key Laboratory of Molecular Imaging Probes and Sensors, Department of Chemistry, Shanghai Normal University, 100 Guilin Road, Shanghai 200234, China.E-mail: huangcs@shnu.edu.cn

$\dagger$ Electronic supplementary information (ESI) available. See DOI: 10.1039/c8cc06917d \$ Equal contribution.
}

Therefore, it is common to find elevated levels of GSH when cells are undergoing oxidative stress. Therefore, the susceptibility of a cell towards $\mathrm{ONOO}^{-}$largely depends on the concentration of intracellular GSH. ${ }^{7,16,17}$

Within our research groups, we are interested in developing small molecule fluorescent probes for the detection of biological reactive oxygen species as well as biological thiols. ${ }^{18-21}$ While many literature reported fluorescent probes have been used to understand the roles of single chemical species, which include metal ions ${ }^{22}$ and reactive oxygen species ${ }^{23,24}$ in biological systems. ${ }^{25}$ Relatively, few probes have been developed to report on the role of two or more analytes in a biological system. In parallel to the development of fluorescent probes, the field of molecular logic gates has developed. ${ }^{26,27}$

Molecular logic gates are molecules that have the ability to bind to multiple analytes and transform the multiple binding events to a measurable output. Recently, we have developed dual activated fluorescent probes. Where, the 'AND' logic operation requires two analytes to produce a positive output signal. These 'AND' logic systems have the ability to detect two different analytes within the same biological sample and hence provide a simple approach for monitoring complex bimolecular events, where two species may be intimately responsible for a particular disease. ${ }^{28}$

Dual fluorescence based probes for monitoring the relationship between $\mathrm{ONOO}^{-}$and $\mathrm{GSH}$ are uncommon, ${ }^{29,30}$ despite numerous fluorescence based probes being developed for the sensing of these analytes separately. ${ }^{31,32}$ Recently, we have developed a fluorescein-based 'AND' logic gate, which was capable of detecting $\mathrm{ONOO}^{-}$'AND' GSH in cells (Fig. 1c). ${ }^{33}$ 'AND' logic based fluorescence probes for $\mathrm{ONOO}^{-}$'AND' GSH are of particular interest as they could potentially be used to evaluate the therapeutic efficacy of a particular treatment towards Alzheimer's disease. ${ }^{34}$

In this work, we set out to improve on our earlier system by developing an excited state intramolecular proton transfer (ESIPT) 'AND' logic gate for the simultaneous detection of $\mathrm{ONOO}^{-}$'AND' GSH. Owing to the attractive characteristics of 
a)

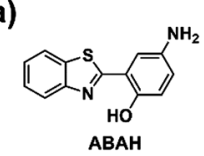

b)

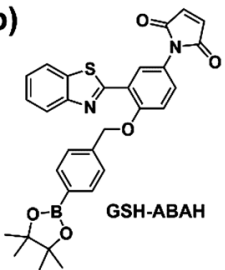

c)

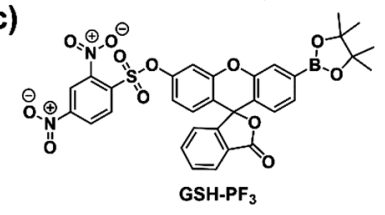

Fig. 1 (a) ABAH ESIPT fluorophore previously used in the literature (b) this work - ESIPT-based probe GSH-ABAH for the detection of $\mathrm{ONOO}^{-}$and biological thiols (c) structure of the GSH-PF3 probe previously used for the simultaneous detection of $\mathrm{ONOO}^{-}$and GSH.

ESIPT fluorophores, which include: ratiometric sensing, large stokes shift and environmental sensitivity. Essentially, if a ratiometric system could be developed then this would be a significant advance, potentially allowing for calibration free monitoring. ${ }^{35-37}$

4-Amino-2-(benzo[d]thiazol-2-yl)phenol (ABAH) was regarded as an ideal ESIPT fluorophore for the development of an 'AND' based fluorescence probe due to having a free phenol and amino group, which can be independently derivatized (Fig. 1 and Scheme S1, ESI $\dagger$ ). ${ }^{36,38-41}$ We believed the functionalization of the free phenolic unit of ABAH with a benzyl boronic ester would block the ESIPT process and serve as the reactive unit for $\mathrm{ONOO}^{-}$. Due to aromatic boronates having a greater reactivity towards $\mathrm{ONOO}^{-}$over $\mathrm{HClO} / \mathrm{ClO}^{-}$and $\mathrm{H}_{2} \mathrm{O}_{2}{ }^{42}$ Previously, the functionalization of the amino group of $\mathbf{A B A H}$ with the thiolreactive maleimide group resulted in the quenching of the fluorescence intensity due to a PET process. However, in the presence of biological thiols the fluorescence intensity was rapidly restored. ${ }^{43}$ Therefore, we thought that the combination of these two reactive units with ABAH would result in an effective PET+ESIPT 'AND'-logic probe for the detection of $\mathrm{ONOO}^{-}$'AND' biological thiols (Fig. 1 and Scheme 1).

To test this hypothesis, we synthesized probe GSH-ABAH over three steps (Scheme S2 - see ESI $\dagger$ ). ABAH was first synthesized in excellent yield (73\%) by heating 2-aminothiophenol and 5-aminosalicylic acid in polyphosphoric acid (PPA) at $180^{\circ} \mathrm{C}$. With ABAH in hand, maleic anhydride was then added to a solution of ABAH in glacial acetic acid. This condensation reaction was performed under reflux for 4 hours to afford the desired intermediate 2 as a yellow solid. 2 was then alkylated using (4-bromomethylphenyl)boronic acid pinacol ester and $\mathrm{K}_{2} \mathrm{CO}_{3}$ in DMF to afford GSH-ABAH in $27 \%$ yield (Scheme S2, ESI $\dagger$ ). The chemical structure of GSH-ABAH was fully characterized by ${ }^{1} \mathrm{H}$ NMR, ${ }^{13} \mathrm{C}$ NMR and high resolution mass spectrometry (HRMS).

We then evaluated the changes in the UV-Vis absorption of GSH-ABAH in the presence of both GSH and $\mathrm{ONOO}^{-}$. The maximum absorption of GSH-ABAH at $326 \mathrm{~nm}$ shifted to $370 \mathrm{~nm}$ with the addition of $\mathrm{ONOO}^{-}$while the absorption peak
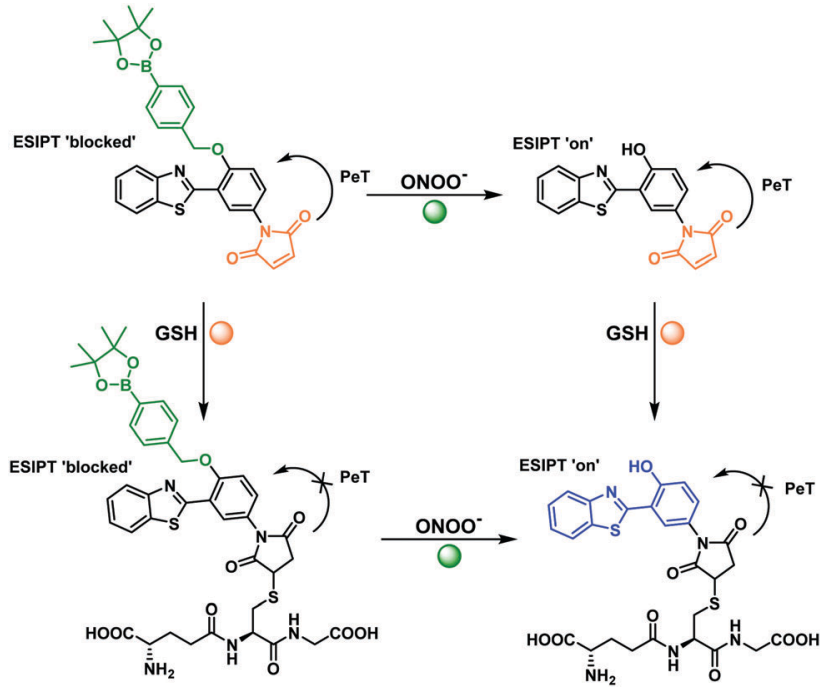

Scheme 1 Fluorescence turn 'on' mechanism of GSH-ABAH in the presence of $\mathrm{ONOO}^{-}$and $\mathrm{GSH}$.

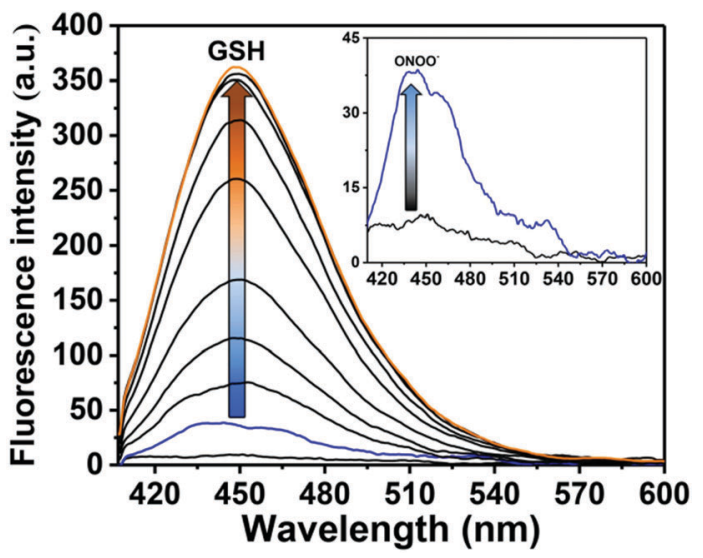

Fig. 2 Fluorescence spectra of GSH-ABAH $(2 \mu \mathrm{M})$ with addition of $\mathrm{ONOO}^{-}(4 \mu \mathrm{M})$ (inset) followed by the addition of GSH $(0-2 \mu \mathrm{M})$, and $1 \mathrm{~min}$ wait in buffer solution [8\% DMSO, $1 \mathrm{mM} \mathrm{CTAB}]\left(\mathrm{pH}=8.20\right.$ at $\left.25^{\circ} \mathrm{C}\right)$ fluorescence intensities were measured with $\lambda_{\mathrm{ex}}=390 \mathrm{~nm} / \lambda_{\mathrm{em}}=451 \mathrm{~nm}$ with slit widths ex slit: $4 \mathrm{~nm}$ and em slit: $4 \mathrm{~nm}$.

does not change with addition of GSH, which is consistent with the PET process (Fig. S1 and S2, ESI $\dagger$ ). Fluorescence experiments with $\mathrm{ONOO}^{-}$were then carried out. As shown in Fig. 2 and Fig. S3 (ESI $\dagger$ ), GSH-ABAH was initially non-fluorescent, however upon the addition of $\mathrm{ONOO}^{-}(4 \mu \mathrm{M})$, a small fluorescence increase was observed. However, a large increase in fluorescence intensity ( $>10$-fold, see Fig. 2 and Fig. S4, ESI $\dagger$ ) was then observed following the subsequent addition of GSH $(0-2 \mu \mathrm{M})$. This observation demonstrated the requirement of both $\mathrm{ONOO}^{-}$'AND' GSH to obtain a significant turn "on" fluorescence response.

The addition of both analytes was then carried out in reverse order. Similarly, the addition of GSH $(5 \mu \mathrm{M})$ only resulted in a small increase in fluorescence intensity (Fig. 3 and Fig. S5, ESI $\dagger$ ). However, as expected a large fluorescence increase was observed after the subsequent addition of $\mathrm{ONOO}^{-}(0-14 \mu \mathrm{M})$ (Fig. 3 and Fig. S6, ESI $†$ ). 


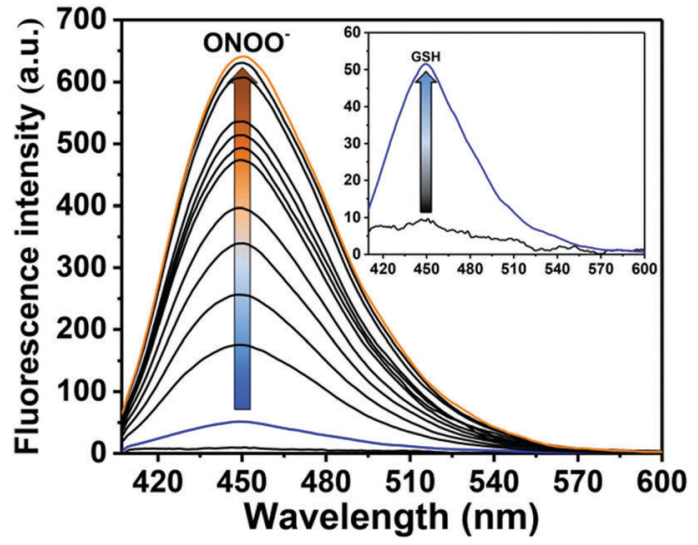

Fig. 3 Fluorescence spectra of GSH-ABAH $(2 \mu \mathrm{M})$ with addition of GSH $(5 \mu \mathrm{M}), 1 \mathrm{~min}$ wait (inset), then addition of $\mathrm{ONOO}^{-}(0-14 \mu \mathrm{M})$ in buffer solution [8\% DMSO, $1 \mathrm{mM} \mathrm{CTAB}]\left(\mathrm{pH}=8.20\right.$ at $\left.25^{\circ} \mathrm{C}\right)$ fluorescence intensities were measured with $\lambda_{\mathrm{ex}}=390 \mathrm{~nm} / \lambda_{\mathrm{em}}=451 \mathrm{~nm}$ with slit widths ex slit: $4 \mathrm{~nm}$ and em slit: $4 \mathrm{~nm}$.

Next, we evaluated the selectivity of probe GSH-ABAH towards a number of biologically relevant amino acids including serine, lysine and methionine (Fig. S7, ESI $\dagger$ ). The amino acids without a thiol (S-H) group led to no change in fluorescence intensity of GSH-ABAH. However, as predicted, thiol (S-H) containing biological analytes (glutathione, cystine and homocystine) induced an enhancement in fluorescence intensity. While GSH-ABAH demonstrated an excellent selectivity for $\mathrm{ONOO}^{-}$over reactive oxygen/nitrogen species including $\mathrm{H}_{2} \mathrm{O}_{2}$ (Fig. S8, ESI $\dagger$ ).

We then carried out kinetic studies for GSH-ABAH with both $\mathrm{ONOO}^{-}$and GSH (Fig. S9 and S10, ESI $\dagger$ ). After initial addition of $\mathrm{GSH}$ or $\mathrm{ONOO}^{-}$, followed by the subsequent addition of the second analyte a significant increase in fluorescence within $30 \mathrm{~s}$ was observed. HRMS experiments were performed, in order to confirm the reaction mechanism. When 2 eq. of $\mathrm{ONOO}^{-}$ (in water) was added to a solution of GSH-ABAH (HRMS in acetonitrile Fig. S11, ESI $\dagger$ ) the mass spectra was consistent with deprotection of the phenol (Fig. S12 (ESI $\dagger$ ) and Scheme 1). Subsequently, 1 eq. GSH (in water) was added a mass peak at 630.1354 was observed confirming the reaction of GSH with the maleic anhydride group via electrophilic addition (Fig. S13 (ESI $\dagger$ ) and Scheme 1). These results clearly demonstrate the ability of GSH-ABAH to perform 'AND' logic with ONOO 'AND' GSH.

Due to these results, GSH-ABAH was then evaluated for cellular imaging of GSH and $\mathrm{ONOO}^{-}$. RAW264.7 cells were pre-treated with $N$-ethylmaleimide (NEM, GSH scavenger) before incubation with GSH-ABAH. Subsequently, GSH or SIN-1 (a peroxynitrite donor) ${ }^{15}$ were added to produce intracellular GSH or $\mathrm{ONOO}^{-}$. As shown in Fig. 4 and Fig. S14 (ESI $\dagger$ ), the addition of $\mathrm{GSH}$ or $\mathrm{ONOO}^{-}$led to no fluorescence response in cells. However, treatment with both GSH and SIN-1 resulted in a significant increase in the fluorescence intensity enabling the visualisation of both species in living cells.

In summary, we have developed an ESIPT-based 'AND' logic fluorescence probe (GSH-ABAH) for the detection of $\mathrm{ONOO}^{-}$and biological thiols. GSH-ABAH was shown to have high sensitivity and selectivity towards $\mathrm{ONOO}^{-}$and biothiols. More importantly,
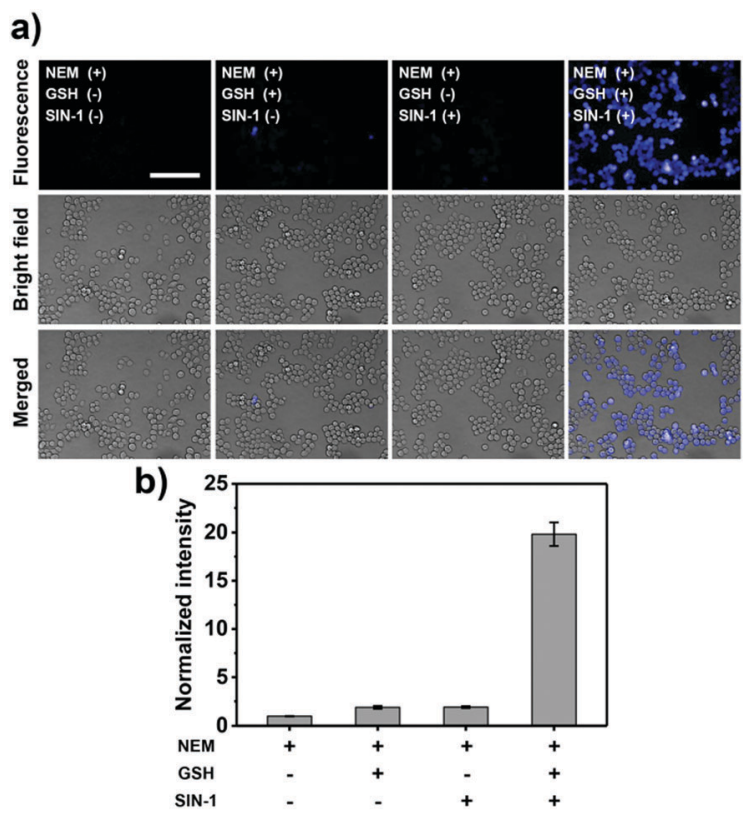

Fig. 4 Fluorescence imaging (a) and quantification (b) of RAW264.7 cells with GSH-ABAH $(20 \mu \mathrm{M})$ in the presence of exogenously added GSH (300 $\mu \mathrm{M})$ and/or SIN-1 (500 $\mu \mathrm{M})$ with 1\% DMSO. Excitation channel $360-400 \mathrm{~nm}$, emission channel filtered $=410-480 \mathrm{~nm}$. Scale bar $=100 \mu \mathrm{m}$. Error bars represent SD. Note: the cells were pre-incubated with $N$-ethylmaleimide (NEM, GSH scavenger).

GSH-ABAH was able to visualise exogenous $\mathrm{ONOO}^{-}$and GSH in RAW264.7 cells. This simple novel 'AND' logic-based system provides a scaffold for the further development of a multianalyte probes. We are now turning our attention to the development of longer wavelength ESIPT-based probes for multi-analyte in vivo imaging.

LW wishes to thank China Scholarship Council and the University of Bath for supporting his PhD work in the UK. We would like to thank the EPSRC and the University of Bath for funding. ACS and JEG thank the EPSRC for a studentship. TDJ wishes to thank the Royal Society for a Wolfson Research Merit Award. X.-P. He thanks the National Natural Science Foundation of China (21722801 and 21572058), the Programme of Introducing Talents of Discipline to Universities (B16017) and the Shanghai Rising-Star Program (16QA1401400). CH would like to thank the National Natural Science Foundation of China (Grants 21672150, and 213021125), Shanghai "Chenguang" Program (Grant 14CG42), and Program for Changjiang Scholars and Innovative (IRT_16R49). NMR characterisation facilities were provided through the Chemical Characterisation and Analysis Facility (CCAF) at the University of Bath (www.bath.ac.uk/ccaf). The EPSRC UK National Mass Spectrometry Facility at Swansea University is thanked for analyses. All data supporting this study are provided as supplementary information accompanying this paper $(\mathrm{ESI} \dagger)$.

\section{Conflicts of interest}

No conflicts of interest. 


\section{Notes and references}

1 C. Szabó, H. Ischiropoulos and R. Radi, Nat. Rev. Drug Discovery, $2007,6,662$.

2 G. Ferrer-Sueta and R. Radi, ACS Chem. Biol., 2009, 4, 161-177.

3 P. Ascenzi, A. di Masi, C. Sciorati and E. Clementi, Biofactors, 2010, 36, 264-273.

4 H. Ischiropoulos and J. S. Beckman, J. Clin. Invest., 2003, 111, 163-169.

5 P. Sarchielli, F. Galli, A. Floridi, A. Floridi and V. Gallai, Amino Acids, 2003, 25, 427-436.

6 D. A. Wink, Y. Vodovotz, J. Laval, F. Laval, M. W. Dewhirst and J. B. Mitchell, Carcinogenesis, 1998, 19, 711-721.

7 P. Pacher, J. S. Beckman and L. Liaudet, Physiol. Rev., 2007, 87, 315-424.

8 J. S. Stamler and A. Slivka, Nutr. Rev., 1996, 54, 1-30.

9 S. Iwata, T. Hori, N. Sato, Y. Ueda-Taniguchi, T. Yamabe, H. Nakamura, H. Masutani and J. Yodoi, J. Immunol., 1994, 152, 5633-5642.

10 H. Nakamura, K. Nakamura and J. Yodoi, Annu. Rev. Immunol., 1997, 15, 351-369.

11 G. Wu, Y.-Z. Fang, S. Yang, J. R. Lupton and N. D. Turner, J. Nutr., 2004, 134, 489-492.

12 S. C. Lu, Mol. Aspects Med., 2009, 30, 42-59.

13 S. Seshadri, A. Beiser, J. Selhub, P. F. Jacques, I. H. Rosenberg, R. B. D'agostino, P. W. Wilson and P. A. Wolf, N. Engl. J. Med., 2002, 346, 476-483.

14 D. M. Townsend, K. D. Tew and H. Tapiero, Biomed. Pharmacother., 2003, 57, 145-155.

15 M. Balazy, P. M. Kaminski, K. Mao, J. Tan and M. S. Wolin, J. Biol. Chem., 1998, 273, 32009-32015.

16 K.-A. Marshall, M. Reist, P. Jenner and B. Halliwell, Free Radical Biol. Med., 1999, 27, 515-520.

17 J. P. Bolaños, S. J. Heales, J. M. Land and J. B. Clark, J. Neurochem., 1995, 64, 1965-1972.

18 A. C. Sedgwick, J. E. Gardiner, G. Kim, M. Yevglevskis, M. D. Lloyd, A. T. A. Jenkins, S. D. Bull, J. Yoon and T. D. James, Chem. Commun., 2018, 54, 4786-4789.

19 M. L. Odyniec, A. C. Sedgwick, A. H. Swan, M. Weber, T. S. Tang, J. E. Gardiner, M. Zhang, Y.-B. Jiang, G. Kociok-Kohn, R. B. Elmes, S. D. Bull, X.-P. He and T. D. James, Chem. Commun., 2018, 54, 8466-8469.

20 L. Wu, Q. Yang, L. Liu, A. C. Sedgwick, A. J. Cresswell, S. D. Bull, C. Huang and T. D. James, Chem. Commun., 2018, 54, 8522-8525.

21 L. Wu, Y. Wang, M. Weber, L. Liu, A. C. Sedgwick, S. D. Bull, C. Huang and T. D. James, Chem. Commun., 2018, 54, 9953-9956.
22 D. Wu, L. Chen, W. Lee, G. Ko, J. Yin and J. Yoon, Coord. Chem. Rev., 2018, 354, 74-97.

23 N. Soh, Anal. Bioanal. Chem., 2006, 386, 532-543.

24 X. Jiao, Y. Li, J. Niu, X. Xie, X. Wang and B. Tang, Anal. Chem., 2017, 90, 533-555.

25 (a) D. Wu, A. C. Sedgwick, T. Gunnlaugsson, E. U. Akkaya, J. Yoon and T. D. James, Chem. Soc. Rev., 2017, 46, 7105-7123; (b) X.-P. He and H. Tian, Chem, 2018, 4, 246-268; (c) Y. Fu, H.-H. Han, J. Zhang, X.-P. He, B. L. Feringa and H. Tian, J. Am. Chem. Soc., 2018, 140, 8671-8674; (d) J. Zhang, Y. Fu, H.-H. Han, Y. Zang, J. Li, X.-P. He, B. L. Feringa and H. Tian, Nat. Commun., 2017, 8, 987.

26 S. Erbas-Cakmak, S. Kolemen, A. C. Sedgwick, T. Gunnlaugsson, T. D. James, J. Yoon and E. U. Akkaya, Chem. Soc. Rev., 2018, 47, 2228-2248.

27 J. L. Kolanowski, F. Liu and E. J. New, Chem. Soc. Rev., 2018, 47, 195-208.

28 (a) A. Romieu, Org. Biomol. Chem., 2015, 13, 1294-1306; (b) X.-P. He, X.-L. Hu, T. D. James, J. Yoon and H. Tian, Chem. Soc. Rev., 2017, 46, 6687-6696.

29 F. Yu, P. Li, G. Li, G. Zhao, T. Chu and K. Han, J. Am. Chem. Soc., 2011, 133, 11030-11033.

30 F. Yu, P. Li, B. Wang and K. Han, J. Am. Chem. Soc., 2013, 135, 7674-7680.

31 S. Wang, L. Chen, P. Jangili, A. Sharma, W. Li, J.-T. Hou, C. Qin, J. Yoon and J. S. Kim, Coord. Chem. Rev., 2018, 374, 36-54.

32 H. S. Jung, X. Chen, J. S. Kim and J. Yoon, Chem. Soc. Rev., 2013, 42, 6019-6031.

33 A. C. Sedgwick, H.-H. Han, J. E. Gardiner, S. D. Bull, X.-P. He and T. D. James, Chem. Sci., 2018, 9, 3672-3676.

34 C. B. Pocernich and D. A. Butterfield, Biochim. Biophys. Acta, Mol. Basis Dis., 2012, 1822, 625-630.

35 V. V. Shynkar, A. S. Klymchenko, C. Kunzelmann, G. Duportail, C. D. Muller, A. P. Demchenko, J. M. Freyssinet and Y. Mely, J. Am. Chem. Soc., 2007, 129, 2187-2193.

36 M. Santra, B. Roy and K. H. Ahn, Org. Lett., 2011, 13, 3422-3425.

37 J. E. Kwon and S. Y. Park, Adv. Mater., 2011, 23, 3615-3642.

38 K. S. Hwang, K. Y. Park, D. B. Kim and S.-K. Chang, Dyes Pigm., 2017, 147, 413-419.

39 Y. Zhao, Y. Xue, H. Li, R. Zhu, Y. Ren, Q. Shi, S. Wang and W. Guo, Spectrochim. Acta, Part A, 2017, 175, 215-221.

$40 \mathrm{H}$. Yao and T. Funada, Chem. Commun., 2014, 50, 2748-2750.

41 L. Cui, W. Zhu, Y. Xu and X. Qian, Anal. Chim. Acta, 2013, 786, 139-145.

42 A. Sikora, J. Zielonka, M. Lopez, J. Joseph and B. Kalyanaraman, Free Radical Biol. Med., 2009, 47, 1401-1407.

43 T. Matsumoto, Y. Urano, T. Shoda, H. Kojima and T. Nagano, Org. Lett., 2007, 9, 3375-3377. 